\title{
Geleneksel Performans Değerlendirme Ölçütlerinin Ekonomik Katma Değere Etkisi: Bilişim Endeksi Uygulaması (XBLSM) \\ (The Effect of Traditional Performance Evaluation Criteria on the Market Value Added: Application on Informatics Index (XBLSM))
}

\section{İlker CALAYOĞLU (iDa}

a İstanbul Okan Üniversitesi, İYBF, Muhasebe ve Denetim Bölümü, İstanbul, Türkiye. ilkercalayoglu@outlook.com

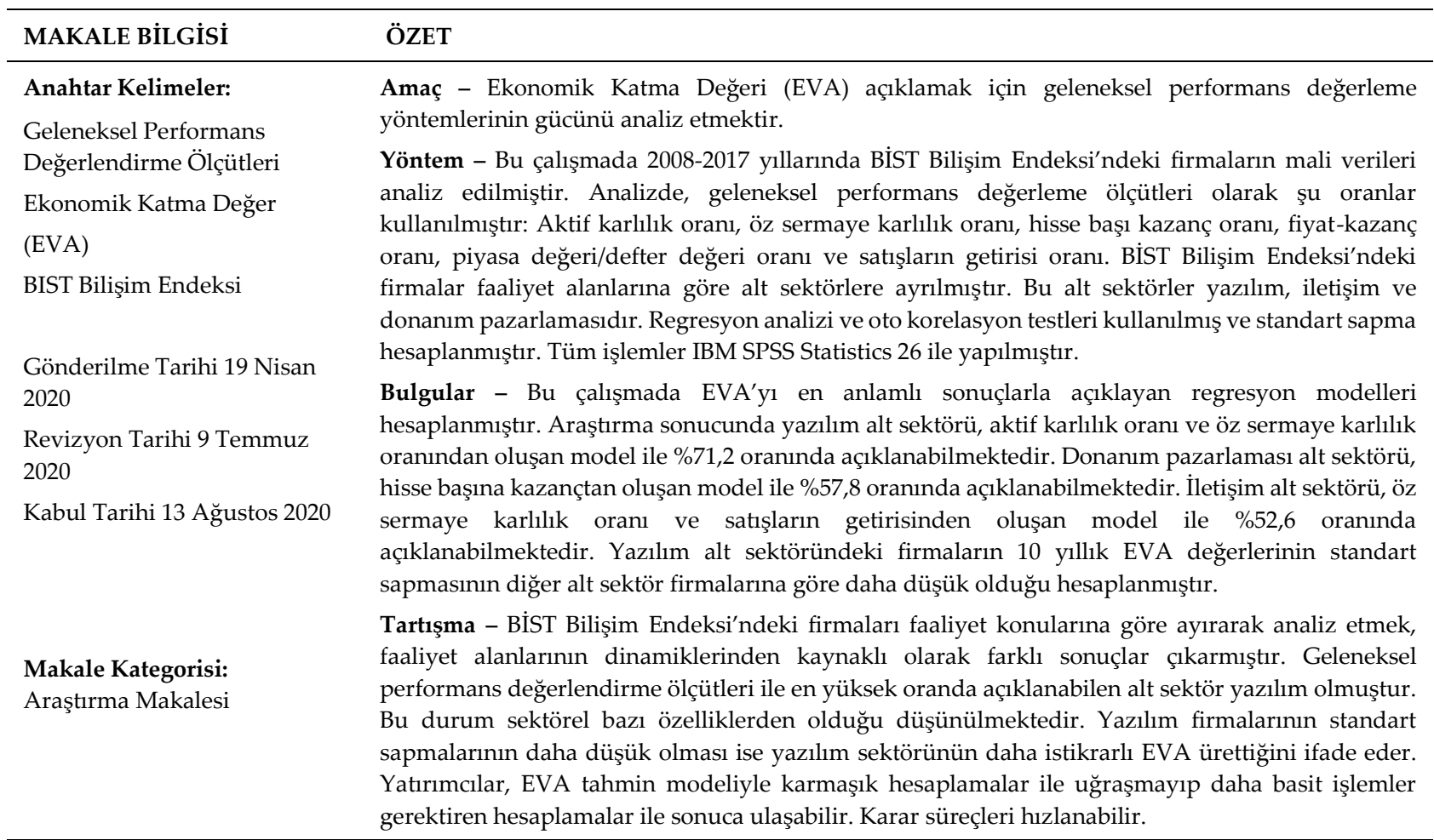

\begin{tabular}{ll}
\hline ARTICLE INFO & ABSTRACT \\
\hline Keywords: & $\begin{array}{l}\text { Purpose - To analyze the power of traditional performance evaluation methods to explain the } \\
\text { Economic Value Added (EVA). }\end{array}$ \\
$\begin{array}{l}\text { Traditional Performance } \\
\text { Evaluation Criteria }\end{array}$ & $\begin{array}{l}\text { Design/methodology/approach - In this study, fiscal data of companies in the BIST Informatics } \\
\text { Index which is period between 2008-2017 years were analyzed. In the analysis the following ratios } \\
\text { Economic Value Added (EVA) } \\
\text { were used as traditional performance evaluation criteria: Return on assets, return on equity, earnings } \\
\text { per share, price to earnings ratio, market to book value ratio and return on sales rate. The companies }\end{array}$ \\
BIST Informatics Index & $\begin{array}{l}\text { in the BIST Informatics Index are divided into sub-sectors according to by field of activity. These } \\
\text { sub-sectors are software, communication and hardware marketing. Regression analysis and auto }\end{array}$ \\
correlation tests were used and standard deviation was calculated. All transactions were done with \\
Received 19 April 2020 & $\begin{array}{l}\text { IBM SPSS Statistics 26. } \\
\text { Revised 9 July 2020 }\end{array}$ \\
Accepted 13 August 2020 & $\begin{array}{l}\text { Findings - In this study, models that explain the EVA with the most meaningful results were } \\
\text { calculated. As a result of the research, the software sub-sector can be explained by 71.2\% with the } \\
\text { model consisting of return on assets and return on equity. The hardware marketing sub-sector can }\end{array}$ \\
\hline
\end{tabular}

\section{Önerilen Atıf/ Suggested Citation}

Calayoğlu, İ. (2020). Geleneksel Performans Değerlendirme Ölçütlerinin Ekonomik Katma Değere Etkisi: Bilişim Endeksi Uygulaması (XBLSM), İşletme Araştırmaları Dergisi, 12 (3), 2543-2555. 
be explained by $57.8 \%$ with the model consisting of earnings per share. Communication sub-sector can be explained by $52.6 \%$ with the model consisting of equity profitability ratio and return on sales. It has been calculated that the standard deviation of the 10-year EVA values of companies in the software sub-sector is lower than that of other sub-sector companies.

Discussion - Analyzing the companies in the BIST Informatics Index by analyzing them according to their fields of activity has yielded different results due to the dynamics of their fields of activity. The sub-sector software, which can be explained at the highest rate with traditional performance evaluation criteria, was software. This situation is thought to be some of the sectorial features. The lower standard deviations of software companies mean that the software industry produces more stable EVA. Investors cannot deal with complex calculations with the EVA estimation model, but can come to the conclusion with calculations that require simpler transactions. Decision processes can speed up.

\section{Gİiş̧}

Günümüz şartlarında firmaların birinci amaçları salt kar değil, sürdürülebilir değer yaratmaktır; markalaşmaktır. Bunun için firmanın hisse senetlerinin değerinin arttırılması ve buna bağlı olarak performans ölçümü temel amaç olmaktadır. Bu amaç, hem firmanın pazar değeri arttırır, hem de yatırımcıların servetlerini arttırıcıdır. Kazan kazan durumu ortaya çıkmaktadır.

İşletmelerin performanslarını değerlendirebilmek için muhasebe verilerine dayalı (geleneksel) ve değere dayalı değerleme ölçütleri olmak üzere iki temel yaklaşım vardır. Muhasebe tabanlı ölçütler, genellikle kârlılık üzerine oranlama yaparken, değer odaklı yöntemler ise firmaların yarattığı (katma) değeri ölçmeye odaklanmıştır.

$\mathrm{Bu}$ çalışmanın amacı, Ekonomik Katma Değeri (Economic Value Added-EVA) açılamak için geleneksel performans değerlendirme ölçütlerinin gücünü analiz etmektir. Yatırımcılar, firmaların gelecekteki finansal tablolarını doğru tahmin etmeyi arzular. Çünkü geleceği doğru tahmin edip, pozisyon alan yatırımcılar kazanç elde eder. EVA, firma sermayesinin katma değer yaratarak yönetildiğini gösterdiği için yatırımcılara gelecek adına pozitif beklenti oluşturur. Bu beklentiyi geleneksel performans değerlendirme ölçütleriyle tahmin etmek yatırımcının karar vermesini kolaylaştıracaktır.

Ulusal literatürde imalat, metal eşya, kimya, turizm ve taşıt araçları sanayisindeki firmalara odaklanılarak regresyon modelleri ile tahmin araştırmaları yapan araştırmacılar olmuştur. Bu çalışmalardaki bulgular genel olarak ilişkinin olmadığı modeller, çok zayıf açılama gücü olan regresyon modeli, anlamsız katsayıların olduğu yüksek açılama gücü olan regresyon modeli ve düşük korelasyona sahip ilişkilerin olduğu değişkenler şeklindedir. (Horasan \& Yılmaz, 2019); (Kuğu \& Kırlı, 2013); (Önal vd., 2006); (Erem \& Akyüz, 2014) Araştırmanın BİST Bilişim Endeksi'ne odaklanarak gerçekleştirilmesi hem endeksi eleştirmek hem de bu çalışmadaki bulgular ile literatüre katkıda bulunmak içindir.

İkinci bölümde araştırmada kullanılan değerleme ölçütleri, formülleriyle birlikte kısaca açıklanmıştır. Üçüncü bölümde araştırma bulguları açıklanmıştır.

\section{PERFORMANS DEĞERLENDIRME ÖLÇÜTLERI}

Performans değerlendirme ölçütleri, literatürde ikiye ayrılmaktadır. Birincisi, muhasebe bilimin ürettiği raporlardan elde edilerek hesaplanan ölçütlerdir. Bunlara geleneksel performans değerlendirme ölçütleri denir. $\mathrm{Bu}$ ölçüm yöntemlerinin en belirgin özelliği, hissedarları temel alan bakış açısı yerine firma faaliyetlerine odaklanmış olmalarıdır. (Weissenrieder, 1997: 1); (Birkan, 2015: 11)

İkincisi ise muhasebe bilgilerinden ve dişındaki bir takım bilgilerden yararlanarak hisse sahibinin çıkarları gözetilerek hesaplanan ölçütlerdir. Bu tip ölçütlere değere dayalı performans değerlendirme ölçütleri denir.

\subsection{Geleneksel Performans Değerlendirme Kriterleri}

Bu tip ölçütler, mali tablolardaki kalemlerin birbirleri oranlanmasına dayalıdır. Muhasebe sürecinin çıktısı olan mali tablolar, geçmiş dönem performansını gösterir. Bu kategorideki ölçütler aşağıdaki gibidir. 


\subsubsection{Aktif Karlılık Oranı (Return on Assets - ROA)}

Firmaların tüm varlıklarını kullanarak bu varlıklar vasıtasıyla ne kadar kar üretebildiğini ölçmeye yarar. Bu oran, aşağıdaki formül ile hesaplanır. (Nakhaei ve Hamid, 2013: 5); (Aydın vd., 2010: 125); (Birkan, 2015: 12)

$=\frac{\text { Net Kar }}{\text { Toplam Varlık }}=\frac{\text { Net Kar }}{\text { Toplam Satış }} \times \frac{\text { Toplam Satış }}{\text { Toplam Varlık }}$

$\mathrm{Bu}$ oran bir karar vericiye firma yönetiminin varlıklarını kazanç elde etmek için ne kadar verimli kullandığına dair bir fikir verir. Oran ne kadar yüksek olursa, firma o kadar az yatırımla daha fazla para kazanıyor demektir.

\subsection{2. Özsermaye Karlılı Oranı (Return on Equity - ROE)}

İşletme sahiplerinin koymuş oldukları bir birim sermayeye isabet eden kar oranını hesaplar. Hesaplamada öz sermaye değeri belirlenirken, dönem başı, dönem sonu veya dönemin ortalama öz sermaye değeri alınabilir. Dönem başı, dönem sonu veya ortalama sermaye arasında büyük değişimler bulunması durumunda ortalama öz sermaye tutarının dikkate alınması daha doğru olacaktır. (Büker, Aşıkoğlu, \& Sevil, 2009, s. 104) Aşağıdaki gibi hesaplanır. (Higgins, 2009: 38); (Birkan, 2015: 14); (Nakhaei ve Hamid, 2013: 5); (Aydın vd., 2010: 125)

$=\frac{\text { Net Kar }}{\text { Ortalama Öz Sermaye }}$

Firmaların öz sermaye karlılıklarının yüksek olması, firmanın yüksek oranda temettü ve bedelsiz hisse senedi dağıtım potansiyeline işaret etmekte eder. Bu oran için yorum yapılabilmesi için firmanın ait olduğu sektör ortalaması ile kıyaslanması gerekir.

\subsubsection{Hisse Başına Kar Oranı (Earnings Per Share - EPS)}

Firmanın belli bir dönemde net kârının hisse senedi sayısına bölünmesi ile bulunur. Aşağıdaki gibi hesaplanır. (Birkan, 2015: 15); (Aydın vd., 2010: 128); (Iltaş ve Kaya, 2018: 153); (Islam vd., 2014: 97)

$=\frac{\text { Net Kar }}{\text { Hisse Senedi Sayısı }}$

"Bu tutar, dönem kârının tamamının ortaklara dă̆ıtılması durumunda her ortağa düsen kâr payını göstermektedir." (Top, 2013: 11) Ne kadar çok o kadar iyi anlamındadır.

\subsubsection{Fiyat/Kazanç Oranı (Price to Earnings Ratio - P/E Ratio)}

F/K oranı, bir firmanın net kârı ile hisse senetlerinin toplam değeri arasındaki ilişkiyi göstermektedir. Aşağıdaki gibi hesaplanır. (Birkan, 2015: 16); (Aydın vd., 2010: 126); (İçke ve Aytürk, 2011: 104-107); (Anderson ve Brooks, 2006: 457-458); (Goodman ve Peavy, 1983: 60)

$=\frac{\text { Hisse Senedi Piyasa Fiyatı }}{\text { Hisse Başına Kar }}$

$\mathrm{Bu}$ oran, firmanın her 1 birimlik hisse basına kârına karşılık olarak yatırımcıların kaç birim ödemeye razı olduklarını göstermektedir. Bu oranın yüksekliği, firmanın hisse senedinin aşırı değerlendiği veya yatırımcıların gelecekte yüksek büyüme oranları bekledikleri anlamına gelir.

\subsubsection{Piyasa Değeri/Defter Değeri Oranı (Market to Book Value Ratio)}

Bu oran, firmanın piyasa değerinin, öz kaynaklarının kaç katı olduğunu gösterir. Oran büyüdükçe, hisse senedinin değer kazandığı anlamı çıkar. Oranın 1'den küçük olması, firmanın hissedarlarına değer üretmediğini gösterir. Aşağıdaki gibi hesaplanır. (Birkan, 2015: 17); (Aydın vd., 2010: 127); (Aslanoğlu ve Zor, 2006: 160); (Hayes, 2020)

$=\frac{\text { Hisse Senedi Piyasa Fiyatı } * \text { Hisse Senedi Sayısı }}{\text { Toplam Varlık }- \text { Toplam Barçlar }}$ 
Bu oranın dayanağı olan muhasebe verilerinde izlenen değerleme yöntemi ve farklı muhasebe uygulamaları, sonuca etki edecektir. Analiz, karşılaştırılabilirlik korunarak sürdürülmelidir. Genellikle oran sonucu birden büyüktür, çünkü yatırımcılar firmaların gelir artışı ve kazanç artışı sağlama yeteneklerine güvenir.

\subsubsection{Satışların Getirisi Oranı (Return on Sales Rate)}

İki gelir tablosu kaleminin birbirine oranlanması ile hesaplanır. Gelir ve satışlar arasındaki ilişkiyi gösteren temel oranlardandır. Her birim satıştan ne kadar kar yaratıldığını ifade eder. Aşağıdaki gibi hesaplanır. (Aydeniz, 2009: 266); (Hayes, 2020)

$$
=\frac{\text { Net Kar }}{\text { Net Satışlar }}
$$

$\mathrm{Bu}$ oran, firmanın satış gelirini ne kadar iyi kullandığını gösteren bir kârlılık ölçüsüdür. Kâr marjı standartları sektöre göre büyük farklılıklar gösterebilir, bu nedenle sadece aynı sektördeki farklı firmaları karşılaştırmak için kullanılmalıdır. Yüksek getiri gösteren firmalar daha az vergi ödemeye ve daha yüksek kar marjına sahip sektörlerde olmaya eğilimlidir.

\subsection{Ekonomik Katma Değer (Economic Value Added-EVA)}

Ekonomik katma değer, değere dayalı performans ölçütlerindendir. Temel hedef, firmaya yatırılan sermayenin maliyetinden fazla faaliyet getirisinin olup olmadığını ölçmektir. Bu bakış açısı yatırımcılara dönüktür. (Çelik, 2002: 23) Aşağıdaki formüller kullanılarak hesaplanır. (Çakıcı, 2008: 10)

$E V A=V S N F K-(A O S M * T Y S)$

VSNFK: Vergi Sonrası Net Faaliyet Karı

AOSM: Ağırlıklı Ortalama Sermaye Maliyeti

TYS: Toplam Yatırılmış Sermaye

VSNFK $=$ Faaliyet Karl $*(1-$ Vergi Oranl $)$

$A O S M=(B Y * B V S M O)+(O ̈ K Y * O ̈ K M O)$

BY: Borç Yüzdesi

BVSMO: Borçların Vergi Sonrası Maliyet Oranı

ÖKY: Öz Kaynak Yüzdesi

ÖKMO: Öz Kaynak Maliyet Oranı

Kaynak: (Çakıcı, 2008: 11)

TYS = Toplam Varlıklar - Kısa Dönem Faizsiz Borçlar

EVA'nın amacı, firmaya sermaye yatırmanın ücretini veya maliyetini ölçmek ve daha sonra iyi bir yatırım olarak değerlendirilmek için yeterli para üretip üretmediğini değerlendirmektir. Ücret, yatırımcıların yatırımlarını değerli kılmak için ihtiyaç duydukları minimum getiriyi temsil etmektedir. Pozitif bir EVA, bir projenin gerekli minimum getiriyi aşan getiri elde ettiğini gösterir. (Chan, 2020)

\section{ARAŞTIRMA VERİ SETI VE BULGULAR}

\subsection{Araştırmanın Amacı ve Önemi}

Araştırmanın amacı, geleneksel performans değerlendirme ölçütlerinin EVA^yı aç1klama gücünü üç alt sektör bazında analiz etmektir. Böylece firma analizlerinde önemli bir değerlendirme ölçütü olan EVA'yı etkileyen geleneksel performans değerlendirme ölçütleri basitçe hesaplandığında karar vericinin sonuca gitmesi kolaylaşmış olacaktır. 


\subsection{Araştırma Yöntemi}

Çalışmaya BİST Bilişim Endeksi'ndeki 13 adet firma dâhil edilmiştir. Firmaların 2008-2017 yıllarına mali tablolarına Kamuya Aydınlatma Platformu (KAP)'nun resmi internet sitesi olan www.kap.gov.tr'den ulaşılmıştır. Her bir firmanın geleneksel performans değerlendirme ölçütleri ve EVA değeri hesaplanmıştır.

BİST Bilişim Endeksi'ndeki firmalar, faaliyet alanlarına göre alt sektörlere ayrılmıştır. Bu alt sektörler yazılım, iletişim ve donanım pazarlaması ifadeleri ile isimlendirilmiştir. Yazılım alt sektöründeki firmalar, yazılım üretir ve satar. İletişim alt sektöründeki firmalar, telekomünikasyon alanında hizmet sağlar. Donanım pazarlaması alt sektöründeki firmalar toptan ve perakende olarak bilgisayar donanım ve parçalarını alıp satar.

EVA'nın bağımlı değişken, geleneksel performans değerlendirme ölçütlerinin bağımsız değişken kabul edildiği toplam 63 regresyon denklemi oluşturulmuştur. EVA'yı en fazla etkileyen ve anlamlılık düzeyi en yüksek olan geleneksel performans değerlendirme ölçütleri (bağımsız değişken) alt sektörler bazında tespit edilmiştir. Regresyon analizinin geçerliliği için oto korelasyon testi olan Durbin-Watson testi uygulanmıştır. Tüm analizler IBM SPSS Statistics 25 ile gerçekleştirilmiştir.

\subsection{Araştırmanın Kapsamı ve Kısıtları}

EVA hesaplaması yapılırken aktifleştirme işlemleri, amortisman düzeltmeleri, karşılık giderleri gibi muhasebe düzeltme kayıtları yapılmamıştır. EVA, sadece gelir tablosu ve bilanço kullanılarak basit olarak hesaplanmıştır.

Sermaye maliyeti hesaplamalarında 2008-2017 dönemini kapsayan Türkiye 10 yıllık tahvil faiz oranlarının ortalamaları hesaplanmış ve \%10 olarak uygulanmıştır.

Kafein Yazılım firması, 11.05.2018 tarihinde BİST'te işlem görmeye başlamıştır. KAP'ta mali verileri 2015 yılından itibaren yayınlanmaya başladığı için 2008-2014 yılları mali verilerine ulaşılamamıştır.

Fonet Bilgi Teknolojileri firması, 04.05.2017 tarihinde BİST'te işlem görmeye başlamıştır. KAP'ta mali verileri 2014 yılından itibaren yayınlanmaya başladığı için 2008-2013 yılları mali verilerine ulaşılamamıştır.

Anel Telekom firmasının faaliyetsiz kalması sebebiyle BİST tarafından borsa kotundan çıkarılmıştır. Firmanın mali verilerine ulaşılamamıştır.

\subsection{Araștırmanın Bulguları}

Araştırmanın yöntemi başlığında açıklandı̆̆ı üzere BİST Bilişim Endeksi'ndeki firmalar üç alt sektörde analiz edilmiştir. Regresyon modeline giren bağımsız değişkenler ve onlara verilen sayısal kodlar aşağıdaki gibidir.

$1=$ Aktif Karlılık

$2=$ Öz Sermaye Karlılı̆̆

3= Hisse Başı Kar

4= Fiyat Kazanç Oranı

$5=$ Piyasa Değeri / Defter Değeri

6= Satışların Getirisi Oranı

\subsubsection{Yazılım Alt Sektörü Bulguları}

Bu başlık altında Logo Yazılım ve Link Bilgisayar firmalarının verileri hesaplanmıştır. İki firmanın müstakil sonuçlarının aritmetik ortalaması ise regresyon modelinin verileri oluşturulmuştur. Veriler tablo 1'dedir. 
Tablo 1. Yazılım Alt Sektörü Değerlendirme Sonuçları

\begin{tabular}{|l|r|r|r|r|r|r|r|}
\hline & $\mathbf{1}$ & $\mathbf{2}$ & $\mathbf{3}$ & $\mathbf{4}$ & $\mathbf{5}$ & \multicolumn{1}{|c|}{$\mathbf{6}$} & \multicolumn{1}{c|}{ EVA } \\
\hline $\mathbf{2 0 0 8}$ & 0,00 & 0,00 & 0,02 & $-942,76$ & 0,77 & 0,00 & $-5.003 .315,48$ \\
\hline $\mathbf{2 0 0 9}$ & $-0,12$ & $-0,14$ & $-0,08$ & $-561,11$ & 1,81 & $-0,31$ & $-6.344 .589,98$ \\
\hline $\mathbf{2 0 1 0}$ & $-0,04$ & $-0,04$ & $-0,04$ & $-6.492,21$ & 3,55 & $-0,07$ & $-3.401 .984,74$ \\
\hline $\mathbf{2 0 1 1}$ & 0,30 & 0,33 & 0,63 & 558,41 & 1,40 & 1,30 & $-1.804 .103,55$ \\
\hline $\mathbf{2 0 1 2}$ & 0,04 & 0,08 & $-0,09$ & 400,62 & 1,92 & $-0,05$ & $134.325,07$ \\
\hline $\mathbf{2 0 1 3}$ & 0,11 & 0,20 & 0,09 & 289,00 & 1,39 & 0,23 & $1.979 .294,35$ \\
\hline $\mathbf{2 0 1 4}$ & 0,10 & 0,18 & 0,06 & $1.249,02$ & 4,89 & 0,18 & $3.047 .534,37$ \\
\hline $\mathbf{2 0 1 5}$ & 0,16 & 0,25 & 0,18 & $1.337,57$ & 5,88 & 0,28 & $6.010 .698,43$ \\
\hline $\mathbf{2 0 1 6}$ & 0,11 & 0,19 & 0,14 & $1.458,85$ & 5,19 & 0,23 & $10.738 .380,62$ \\
\hline $\mathbf{2 0 1 7}$ & 0,14 & 0,21 & 0,35 & $1.486,61$ & 5,41 & 0,30 & $3.312 .874,48$ \\
\hline
\end{tabular}

Regresyon analizi için 6 tane bağımsız değişken ve bir bağımlı değişken (EVA) derlenmiştir. 6 bağımsız değişken için tüm alt kümelerin toplamı 63'dür. Her alt küme için regresyon hesaplaması yapılmıştır. En iyi 5 model, Tablo 2'de listelenmiştir. Tablo 2'deki sıralama, önce modelde bulunan bağımsız değişkenlerin katsayılarının anlamsız olma miktarına (az olan değerlidir.) göre ve sonra modelin açıklama gücüne göredir. Oto korelasyon olan modeller * ile işaretlenmiştir.

Tablo 2. Yazılım Alt Sektörü Regresyon Modelleri ve Sonuçları (İlk 5)

\begin{tabular}{|r|r|r|r|r|}
\hline $\begin{array}{c}\text { Regresyon } \\
\text { Modeli }\end{array}$ & \multicolumn{1}{|c|}{$\begin{array}{c}\text { Düzeltilmiş } \\
\mathbf{R}^{\mathbf{2}}\end{array}$} & $\begin{array}{c}\text { Durbin Watson } \\
\text { Test Değeri }\end{array}$ & $\begin{array}{c}\text { Anova- } \\
\text { Sig }\end{array}$ & $\begin{array}{c}\text { Modeldeki Bağımsız Değişken Anlamsızlık } \\
\text { Katsayılarının Sayısı }\end{array}$ \\
\hline 1,2 & 0,712 & 1,728 & 0,005 & 0 \\
\hline 2,6 & 0,685 & 2,030 & 0,007 & 0 \\
\hline 1,6 & 0,609 & 2,200 & 0,016 & 0 \\
\hline 5 & 0,492 & 1,688 & 0,014 & 0 \\
\hline 2 & 0,357 & 1,555 & 0,040 & 0 \\
\hline
\end{tabular}

Tablo 2'de beşinci sırada bulunan 1 ve 2 değişkenleri ile en iyi sonuçlar elde edilmiştir. Bundan sonra sunulacak olan sonuçlar, bu regresyon modelinin açıklamasıdır.

Hata terimindeki oto korelasyonu tespit etmenin yöntemlerinden bir tanesi Durbin-Watson istatistiğidir. Sonuçları okumak için tablo 3 yardımcı olmaktadır.

Tablo 3. Durbin-Watson Testi Karar Alanları

\begin{tabular}{|c|c|c|c|c|}
\hline $\mathrm{H}_{0} \mathrm{Red}$ & \multirow{2}{*}{ Kararsızlık Bölgesi } & $\mathrm{H}_{0}$ ve $\mathrm{H}_{0}{ }^{*} \mathrm{Kabul}$ & \multirow[b]{2}{*}{ Kararsızlık Bölgesi } & $\mathrm{H}_{0}{ }^{*} \mathrm{Red}$ \\
\hline $\begin{array}{c}\text { Pozitif } \\
\text { Otokorelasyon Var. }\end{array}$ & & $\begin{array}{l}\text { Pozitif veya negatif } \\
\text { Otokorelasyon yok. }\end{array}$ & & $\begin{array}{c}\text { Negatif } \\
\text { Otokorelasyon Var. }\end{array}$ \\
\hline$(1)$ & $(2)$ & (3) & (4) & (5) \\
\hline 0 & $\mathrm{~d}_{\mathrm{L}}$ & 2 & $4-\mathrm{du}$ & \\
\hline
\end{tabular}

Kaynak: (Uysal \& Günay, 2001, s. 279) 
Durbin Watson test değerinin anlamı, bağımsız değişken sayısına ve modeldeki gözlem sayısına bağlı olarak anlaşılabilir. Çünkü bu faktörlerdeki değişiklik dL ve dU değerlerini değiştirir. (Draper \& Smith, 1998, s. 130); (Yavuz, 2009, s. 130) Bunları tablo 4'te görmek mümkündür.

Tablo 4. Durbin-Watson Testi \%5 Anlamlılık Seviyesi İçin Kritik Değerler

\begin{tabular}{|c|c|c|c|c|r|r|r|r|r|r|}
\hline & \multicolumn{2}{|c|}{$\mathrm{k}=1$} & \multicolumn{2}{c|}{$\mathrm{k}=2$} & \multicolumn{2}{c|}{$\mathrm{k}=3$} & \multicolumn{2}{c|}{$\mathrm{k}=4$} & \multicolumn{2}{c|}{$\mathrm{k}=5$} \\
\hline Say1 & $\mathrm{dL}$ & $\mathrm{du}$ & $\mathrm{dL}$ & $\mathrm{du}$ & $\mathrm{dL}$ & $\mathrm{du}$ & $\mathrm{dL}$ & $\mathrm{du}$ & $\mathrm{dL}$ & $\mathrm{du}$ \\
\hline 6 & 0,610 & 1,400 & & & & & & & & \\
\hline 7 & 0,700 & 1,356 & 0,467 & 1,896 & & & & & & \\
\hline 8 & 0,763 & 1,332 & 0,559 & 1,777 & 0,367 & 2,287 & & & & \\
\hline 9 & 0,824 & 1,320 & 0,629 & 1,699 & 0,455 & 2,128 & 0,296 & 2,588 & & \\
\hline 10 & 0,879 & 1,320 & 0,697 & 1,641 & 0,525 & 2,016 & 0,376 & 2,414 & 0,243 & 2,822 \\
\hline
\end{tabular}

Kaynak: (http://kisi.deu.edu.tr, 2020)

Tablo 5. Yazılım Alt Sektörü Regresyon Modeli Özeti

\begin{tabular}{|l|c|c|r|r|r|}
\hline Model & $\mathbf{R}$ & $\mathbf{R}^{2}$ & Düzeltilmiş $\mathbf{R}^{2}$ & Tahmindeki Standart Hata & Durbin-Watson \\
\hline 1 &, $881^{\mathrm{a}}$ &, 776 &, 712 & $2.818 .383,560$ & 1,728 \\
\hline
\end{tabular}

Tablo 5'de belirtilen modelin açıklama gücü \%71,2'dir. Bu oran, açıklama gücü açısından oldukça yüksektir. Ayrıca Durbin-Watson test değeri 1,728' dir. Tablo 4'e göre 0,679-1,641 arasındaki kararsızlık bölgesinde değildir. Oto korelasyon olmadığı tespit edilmiştir.

Tablo 6. Yazılım Alt Sektörü Regresyon Modelinin Anova Sonuçları

\begin{tabular}{|l|l|r|r|r|r|r|}
\hline \multicolumn{2}{|l|}{ Model } & Karelerin Toplamı & df & Kareli Ortalama & F & Sig. \\
\hline \multirow{2}{*}{1} & Regresyon & $192.636 .489 .693 .340,900$ & 2 & $96.318 .244 .846 .670,450$ & 12,126 &, $005^{\mathrm{b}}$ \\
\cline { 2 - 7 } & Artık & $55.603 .001 .256 .077,836$ & 7 & $7.943 .285 .893 .725,405$ & & \\
\cline { 2 - 7 } & Toplam & $248.239 .490 .949 .418,750$ & 9 & & & \\
\hline
\end{tabular}

Tablo 6'da yer alan sig değeri 0,05'ten küçük olduğu için, sosyal bilimler açısından anlamlı kabul edilebilen bir regresyon modelidir.

Tablo 7. Yazılım Alt Sektörü Regresyon Modeli Katsayıları

\begin{tabular}{|l|r|r|r|r|r|}
\hline \multirow{2}{*}{ Model } & \multicolumn{2}{|c|}{ Standardize Edilmemiş Katsayılar } & \multirow{2}{*}{$\begin{array}{c}\text { Standart Katsayılar } \\
\text { Beta }\end{array}$} & \multirow{2}{*}{ Sig. } \\
\cline { 2 - 3 } & \multicolumn{1}{c|}{ B } & Standart Hata & & $-3,094$ &, 017 \\
\hline (Sabit) & $-4.230 .045,561$ & $1.367 .120,142$ & $-2,632$ & $-3,294$ &, 013 \\
\hline Aktif Karlılık & $-118.223 .242,416$ & $35.888 .154,267$ & 3,220 & 4,030 &, 005 \\
\hline Öz Sermaye Karlığ $^{2}$ & $115.514 .415,165$ & $28.661 .909,303$ & & \\
\hline
\end{tabular}

Tablo 7'de belirtilen modeldeki her bağımsız değişkenin sig değeri 0,05'ten küçük olduğundan tüm katsayılar kabul edilebilir durumdadır. Buna göre regresyon denklemi aşağıdaki gibidir.

$\mathrm{EVA}=\mathrm{a} 0+\beta_{1}($ Aktif Karlılık $)+\beta_{2}($ Öz Sermaye Karlığı $)+e$, 
EVA $=-4.230 .045,561+\left(-118.223 .242,416^{*}\right.$ Aktif Karlılık $)+\left(115.514 .415,165^{*}\right.$ Öz Sermaye Karlı̆̆1 $)+e$

\subsubsection{Donanım Pazarlaması Alt Sektörü Bulguları}

Bu başlık altında Arena Bilgisayar, Armada Bilgisayar, Datagate Bilgisayar, Despec Bilgisayar, Escort Bilgisayar, İndeks Bilgisayar, Plastikkart firmalarının verileri hesaplanmıştır. Tüm firmaların müstakil sonuçlarının aritmetik ortalaması ise regresyon modelinin verisini oluşturmuştur. Veriler tablo 8'dedir.

Tablo 8. Donanım Pazarlaması Alt Sektörü Değerlendirme Sonuçları

\begin{tabular}{|l|r|r|r|r|r|r|r|}
\hline & $\mathbf{1}$ & $\mathbf{2}$ & $\mathbf{3}$ & $\mathbf{4}$ & $\mathbf{5}$ & \multicolumn{1}{|c|}{$\mathbf{6}$} & \multicolumn{1}{c|}{ EVA } \\
\hline $\mathbf{2 0 0 8}$ & 0,02 & 0,03 & 0,04 & 296,67 & 0,34 & $-0,00$ & $-982.365,45$ \\
\hline $\mathbf{2 0 0 9}$ & 0,07 & 0,17 & 0,22 & 435,59 & 0,65 & 0,04 & $3.065 .389,09$ \\
\hline $\mathbf{2 0 1 0}$ & 0,05 & 0,12 & 0,18 & $3.423,75$ & 0,95 & 0,02 & $2.104 .641,48$ \\
\hline $\mathbf{2 0 1 1}$ & 0,05 & 0,13 & 0,24 & 492,09 & 0,77 & 0,02 & $3.566 .697,78$ \\
\hline $\mathbf{2 0 1 2}$ & 0,06 & 0,13 & 0,14 & 457,39 & 1,04 & 0,03 & $-1.701 .013,35$ \\
\hline $\mathbf{2 0 1 3}$ & 0,06 & 0,10 & 0,07 & 477,98 & 0,73 & 2,61 & $-3.526 .269,02$ \\
\hline $\mathbf{2 0 1 4}$ & 0,04 & 0,13 & 0,26 & $5.859,25$ & 1,10 & 0,47 & $-7.579 .742,00$ \\
\hline $\mathbf{2 0 1 5}$ & 0,05 & 0,15 & 0,53 & 891,31 & 1,16 & 0,17 & $-14.216 .262,19$ \\
\hline $\mathbf{2 0 1 6}$ & 0,05 & 0,14 & 0,31 & 658,85 & 1,24 & 0,45 & $-12.779 .463,73$ \\
\hline $\mathbf{2 0 1 7}$ & 0,05 & 0,16 & 0,63 & $1.477,06$ & 1,45 & 0,15 & $-18.576 .153,86$ \\
\hline
\end{tabular}

Regresyon analizi için 6 tane bağımsız değişken ve bir bağımlı değişken (EVA) derlenmiştir. 6 bağımsız değişken için tüm alt kümelerin toplamı 63'dür. Her alt küme için regresyon hesaplaması yapılmıştır. En iyi 5 model, Tablo 9'da listelenmiştir. Tablo 9'daki sıralama, önce modelde bulunan bağımsız değişkenlerin katsayılarının anlamsız olma miktarına (az olan değerlidir.) göre ve sonra modelin açıklama gücüne göredir. Oto korelasyon olan modeller * ile işaretlenmiştir.

Tablo 9. Donanım Pazarlaması Alt Sektörü Regresyon Modelleri ve Sonuçları (İlk 5)

\begin{tabular}{|r|r|r|r|r|}
\hline $\begin{array}{c}\text { Regresyon } \\
\text { Modeli }\end{array}$ & $\begin{array}{c}\text { Düzeltilmiş } \\
\mathbf{R}^{2}\end{array}$ & $\begin{array}{c}\text { Durbin Watson } \\
\text { Test Değeri }\end{array}$ & $\begin{array}{c}\text { Anova- } \\
\text { Sig }\end{array}$ & $\begin{array}{c}\text { Modeldeki Bağımsız Değişken Anlamsızlık } \\
\text { Katsayılarının Sayısı }\end{array}$ \\
\hline 3 & 0,578 & 1,31 & 0,007 & 0,00 \\
\hline 5 & 0,552 & $1,05^{*}$ & 0,008 & 0,00 \\
\hline 3,6 & 0,634 & 1,93 & 0,012 & 1,00 \\
\hline 1,5 & 0,619 & 1,71 & 0,014 & 1,00 \\
\hline 2,3 & 0,618 & $1,37^{*}$ & 0,014 & 1,00 \\
\hline
\end{tabular}

* Tablo 4'e göre oto korelasyon vardır.

Tablo 9'da birinci sırada bulunan 3 değişkeni ile en iyi sonuçlar elde edilmiştir. Bundan sonra sunulacak olan sonuçlar, bu regresyon modelinin açıklamasıdır.

Tablo 10. Donanım Pazarlaması Regresyon Modeli Özeti

\begin{tabular}{|l|c|c|r|r|r|}
\hline Model & $\mathbf{R}$ & $\mathbf{R}^{2}$ & Düzeltilmiş $\mathbf{R}^{\mathbf{2}}$ & Tahmindeki Standart Hata & Durbin-Watson \\
\hline 1 &, $790^{\mathrm{a}}$ &, 625 &, 578 & 5100084,070 & 1,312 \\
\hline
\end{tabular}


Tablo $10^{\prime}$ da belirtilen modelin açıklama gücü \%57,8'dir. Bu oran, açıklama gücü açısından orta seviyededir. Durbin-Watson test değeri 1,312' dir. Tablo 4'e göre tek bağımsız değişkenli modelin kararsızlık bölgesi 0,879-1,32 aralığıdır. Modelin değeri sınırdadır. Oto korelasyon olmadığı kabul edilmiştir.

Tablo 11. Donanım Pazarlaması Alt Sektörü Regresyon Modelinin Anova Sonuçları

\begin{tabular}{|l|l|l|r|r|r|c|}
\hline \multicolumn{2}{|l|}{ Model } & Karelerin Toplami & df & Kareli Ortalama & F & Sig. \\
\hline \multirow{3}{*}{1} & Regresyon & $346.412 .027 .654 .587,500$ & 1 & $346.412 .027 .654 .587,500$ & 13,318 &, $007 \mathrm{~b}$ \\
\cline { 2 - 7 } & Artık & $208.086 .860 .148 .211,600$ & 8 & $26.010 .857 .518 .526,450$ & & \\
\cline { 2 - 7 } & Toplam & $554.498 .887 .802 .799,100$ & 9 & & & \\
\hline
\end{tabular}

Tablo 11 'de yer alan sig değeri 0,05'ten küçük olduğu için, sosyal bilimler açısından anlamlı kabul edilebilen bir regresyon modelidir.

Tablo 12. Donanım Pazarlaması Alt Sektörü Regresyon Modeli Katsayıları

\begin{tabular}{|c|c|c|c|c|c|c|}
\hline \multirow{2}{*}{\multicolumn{2}{|c|}{ Model }} & \multicolumn{2}{|c|}{ Standardize Edilmemiş Katsayılar } & \multirow{3}{*}{$\begin{array}{c}\text { Standart Katsayılar } \\
\text { Beta }\end{array}$} & \multirow{3}{*}{$\begin{array}{c}\mathbf{t} \\
1,245\end{array}$} & \multirow{3}{*}{$\begin{array}{l}\text { Sig. } \\
, 248 \\
\end{array}$} \\
\hline & & \multirow{2}{*}{$\frac{\text { B }}{3.563 .786,459}$} & \multirow{2}{*}{\begin{tabular}{r|}
\multicolumn{1}{c}{ Standart Hata } \\
$2.861 .541,964$ \\
\end{tabular}} & & & \\
\hline 1 & Sabit & & & & & \\
\hline & Hisse Başı Kar & $-32.924 .582,383$ & $9.021 .964,810$ &,- 790 & $-3,649$ & ,007 \\
\hline
\end{tabular}

Tablo 12' de belirtilen modeldeki her bağımsız değişkenin sig değeri 0,05'ten küçük olduğundan tüm katsayılar kabul edilebilir durumdadır. Buna göre regresyon denklemi aşağıdaki gibidir.

$\mathrm{EVA}=\mathrm{a}_{0}+\beta_{1}$ (Hisse Başı Kar) $+\mathrm{e}$

$\mathrm{EVA}=3.563 .786,459+\left(-32.924 .582,383^{*}\right.$ Hisse Başı Kar $)+\mathrm{e}$

\subsection{3. İletişim Alt Sektörü Bulguları}

İletişim alt sektöründe Alcatel, Karel Elektrik, Kron Telekom ve Netaş Telekomünikasyon firmalarının verileri hesaplanmıştır. Tüm firmaların müstakil sonuçlarının aritmetik ortalaması ise regresyon modelinin verisini oluşturmuştur. Bu veriler tablo 13'dedir.

Tablo 13. İletişim Alt Sektörü Değerlendirme Sonuçları

\begin{tabular}{|c|c|c|c|c|c|c|c|}
\hline & 1 & 2 & 3 & 4 & 5 & 6 & EVA \\
\hline 2008 & 0,05 & 0,35 & 0,28 & 135,51 & 0,21 & 0,06 & $-10.490 .338,50$ \\
\hline 2009 & 0,06 & 0,24 & 0,31 & 307,86 & 0,68 & 0,08 & $-12.011 .140,00$ \\
\hline 2010 & 0,10 & 0,27 & 1,65 & $6.990,14$ & 0,78 & 0,12 & $-15.264 .865,02$ \\
\hline 2011 & 0,04 & 0,01 & 0,15 & $-125,64$ & 1,13 & 0,08 & $-21.748 .821,26$ \\
\hline 2012 & $-0,05$ & $-0,02$ & $-0,02$ & 853,29 & 1,72 & $-0,13$ & $-19.831 .338,90$ \\
\hline 2013 & 0,01 & $-0,03$ & 0,09 & $3.853,43$ & 1,13 & 0,04 & $-28.723 .826,10$ \\
\hline 2014 & 0,04 & 0,07 & 0,09 & $-3.481,04$ & 1,23 & 0,07 & $-27.606 .562,18$ \\
\hline 2015 & 0,09 & 0,18 & 0,14 & 777,01 & 2,05 & 0,14 & $-32.849 .936,74$ \\
\hline 2016 & 0,11 & 0,18 & 0,27 & $1.057,57$ & 1,48 & 0,15 & $-22.767 .421,95$ \\
\hline 2017 & 0,08 & 0,14 & 0,28 & 823,40 & 2,93 & 0,12 & $-24.685 .616,53$ \\
\hline
\end{tabular}


Regresyon analizi için 6 tane bağımsız değişken ve bir bağımlı değişken (EVA) derlenmiştir. 6 bağımsız değişken için tüm alt kümelerin toplamı 63'dür. Her alt küme için regresyon hesaplaması yapılmıştır. En iyi 5 model, Tablo 14'de listelenmiştir. Tablo 14'deki sıralama, önce modelde bulunan bağımsız değişkenlerin katsayılarının anlamsız olma miktarına (az olan değerlidir.) göre ve sonra modelin açılama gücüne göredir. Oto korelasyon olan modeller * ile işaretlenmiştir.

Tablo 14. İletişim Alt Sektörü Regresyon Modelleri ve Sonuçları (İlk4)

\begin{tabular}{|r|r|r|r|r|}
\hline $\begin{array}{c}\text { Regresyon } \\
\text { Modeli }\end{array}$ & \multicolumn{1}{c|}{$\begin{array}{c}\text { Düzeltilmiş } \\
\mathbf{R}^{2}\end{array}$} & $\begin{array}{c}\text { Durbin Watson } \\
\text { Test Değeri }\end{array}$ & $\begin{array}{c}\text { Anova- } \\
\text { Sig }\end{array}$ & $\begin{array}{c}\text { Modeldeki Bağımsız Değişken Anlamsızlık } \\
\text { Katsayılarının Sayısı }\end{array}$ \\
\hline 5 & 0,644 & $1,10^{*}$ & 0,045 & 0,00 \\
\hline 2,6 & 0,526 & 1,68 & 0,030 & 0,00 \\
\hline 1,2 & 0,503 & $1,50^{*}$ & 0,036 & 1,00 \\
\hline $2,5,6$ & 0,577 & $1,28^{*}$ & 0,043 & 2,00 \\
\hline
\end{tabular}

* Tablo 4'e göre oto korelasyon vardır.

Tablo 14'de ikinci sırada bulunan 2 ve 6 değişkenleri ile en iyi sonuçlar elde edilmiştir. Bundan sonra sunulacak olan sonuçlar, bu regresyon modelinin açıklamasıdır.

Tablo 15. İletişim Alt Sektörü Regresyon Modeli Özeti

\begin{tabular}{|l|c|c|r|r|r|}
\hline Model & \multicolumn{1}{|c|}{$\mathbf{R}$} & \multicolumn{1}{|c|}{$\mathbf{R}^{2}$} & Düzeltilmiş $\mathbf{R}^{2}$ & Tahmindeki Standart Hata & Durbin-Watson \\
\hline 1 &, $795^{\mathrm{a}}$ &, 632 &, 526 & $5.040 .769,612$ & 1,675 \\
\hline
\end{tabular}

Tablo $15^{\prime}$ de belirtilen modelin açıklama gücü \%52,6'dır. Bu oran, açıklama gücü açısından orta seviyededir. Durbin-Watson test değeri 1,675'dir. Tablo 4'e göre iki bağımsız değişkenli modelin kararsızlık bölgesi 0,697-1,641 aralığıdır. Modelin değeri sınırı geçmiştir. Oto korelasyon tespit edilmemiştir.

Tablo 16. İletişim Alt Sektörü Regresyon Modelinin Anova Sonuçları

\begin{tabular}{|l|l|r|r|r|r|c|}
\hline \multicolumn{2}{|l|}{ Model } & Karelerin Toplamı & df & Kareli Ortalama & F & Sig. \\
\hline \multirow{3}{*}{1} & Regresyon & $305.062 .178 .882 .002,800$ & 2 & $152.531 .089 .441 .001,400$ & 6,003 &, $030^{\mathrm{b}}$ \\
\cline { 2 - 7 } & Artık & $177.865 .507 .956 .836,700$ & 7 & $25.409 .358 .279 .548,098$ & & \\
\cline { 2 - 7 } & Toplam & $482.927 .686 .838 .839,500$ & 9 & & & \\
\hline \hline
\end{tabular}

a. Bağımlı Değişken: EVA

b. Tahminler: (Sabit), Öz Sermaye Karlılı̆̆ı, Satışların Getirisi

Tablo 16' de yer alan sig değeri 0,05'ten küçük olduğu için, sosyal bilimler açısından anlamlı kabul edilebilen bir regresyon modelidir.

Tablo 17. İletişim Alt Sektörü Regresyon Modeli Katsayıları

\begin{tabular}{|c|c|c|c|c|c|c|}
\hline \multirow{2}{*}{\multicolumn{2}{|c|}{ Model }} & \multicolumn{2}{|c|}{ Standardize Edilmemiş } & \multirow{3}{*}{$\begin{array}{c}\text { Standart Katsayılar } \\
\text { Beta }\end{array}$} & \multirow{3}{*}{$\begin{array}{c}\mathbf{t} \\
-9,755\end{array}$} & \multirow{3}{*}{$\begin{array}{l}\text { Sig. } \\
, 000\end{array}$} \\
\hline & & \multirow{2}{*}{$\begin{array}{c}\text { В } \\
-24.520 .707,996 \\
\end{array}$} & \multirow{2}{*}{\begin{tabular}{|r|} 
Standart Hata \\
$2.513 .572,600$
\end{tabular}} & & & \\
\hline 1 & (Sabit) & & & & & \\
\hline & Öz Sermaye Karlılığı & $51.119 .128,407$ & $15.086 .792,220$ & ,902 & 3,388 & ,012 \\
\hline & Satışların Getirisi & $-57.299 .144,801$ & $24.426 .258,947$ &,- 625 & $-2,346$ & ,051 \\
\hline
\end{tabular}




\section{İ. Calayoğlu 12/3 (2020) 2543-2555}

Tablo 17'de belirtilen modeldeki her bağımsız değişkenin sig değeri 0,05'ten küçük olduğundan tüm katsayılar kabul edilebilir durumdadır. Buna göre regresyon denklemi aşağıdaki gibidir.

$E V A=a_{0}+\beta_{1}($ Öz Sermaye Karlılı̆̆ $)+\beta_{2}($ Satışların Getirisi $)+e$,

EVA $=-24.520 .707,996+\left(51.119 .128,407^{*}\right.$ Öz Sermaye Karlılı̆̆1 $)+\left(-57.299 .144,801^{*}\right.$ Satışların Getirisi $)+e$

\section{SONUÇ ve TARTIŞMA}

Bu çalışmada BİST Bilişim Endeksi'nde bulunan ve veri kesintisine uğramayan 13 firmanın 2008 ve 2017 yılları arasındaki 10 yıllık finansal değerleri incelenmiştir. Geleneksel performans değerlendirme yöntemleri ve EVA sonuçları hesaplanmıştır.

Bu çalışmada BİST Bilişim Endeksi'ndeki firmaları faaliyet konularına göre ayırarak analiz etmek, farklı sonuçlar çıkarmıştır.

Yazılım alt sektörü regresyon çalışmasında; EVA'yı en çok ve en anlamlı etkileyen regresyon modeli \%71,2 oranında açıklanma gücü olan, oto korelasyon bulunmayan 1 ve 2 kodlu ölçütler ile çoklu regresyon modeli olmuştur. Bu modeldeki ölçütler şunlardır: Aktif Karlılık ve Öz Sermaye Karlılığı. Bu ölçütlerin ortak noktası, net kar tutarıdır. Hesaplama formüllerinde pay kısmında net kar bulunmaktadır.

Donanım pazarlaması alt sektörü regresyon çalışmasında; EVA'yı en çok ve en anlamlı etkileyen \%57,8 oranında açıklanma gücü olan, oto korelasyon bulunmayan sadece 3 kodlu bağımsız değişkenin olduğu Hisse Başı Kar ölçütüdür. Basit regresyon modelidir.

İletişim alt sektörü regresyon çalışmasında; EVA'yı en çok ve en anlamlı etkileyen regresyon modeli \%52,6 oranında açıklanma gücü olan, oto korelasyon bulunmayan 2 ve 6 kodlu bağımsız değişkenlerin olduğu Öz Sermaye Karlılığı ve Satışların Getirisi ölçütleridir. Çoklu regresyon modelidir. Bu ölçütlerin ortak noktası, net kar tutarıdır. Hesaplama formüllerinde pay kısmında net kar bulunmaktadır.

Geleneksel performans değerlendirme ölçütleri ile en yüksek oranda ve anlamlı olarak açıklanabilen alt sektör yazılımdir.

Yazılım alt sektöründeki firmaların 10 yıllık EVA değerleri incelendiğinde standart sapmasının diğer alt sektör firmalarına göre daha düşük olduğu hesaplanmıştır. Yazılım 5.251.872,59; iletişim 7.325.205,24; donanım pazarlaması 7.849.266,69'dur. Buradan anlaşılacağı üzere yazılım firmalarının EVA değerleri daha istikrarlı ve değişim aralığı daha düşüktür. Ayrıca Tablo 1, 8 ve 13 karşılaştırıldığında yazılım alt sektörü firmalarının EVA değerleri mukayeseli olarak daha pozitiftir. Kısaca BİST Bilişim Endeksi'ndeki yazılım üreten firmaların ekonomik katma değer üretme ve daha istikrarlı olmaları bakımından diğerlerine göre üstündür.

BİST Bilişim Endeksi'nde yer alan firmaların sermaye tutarları incelendiğinde; yazılım faaliyetinde bulunan firmaların, iletişim ve donanım pazarlaması faaliyetlerinde bulunan firmalara göre sermaye tutarlarının daha düşük olduğu gözlemlenmiştir. Bunun en önemli nedeni, yazılım firmalarının sermayeden çok emek yoğun çalışmaları ve entelektüel sermaye birikimine sahip olmaları olarak gösterilebilir. Bu durum, yazılım firmalarının daha pozitif EVA üretmeleri için gerçekçi bir nedendir.

2008-2017 yılları arasında 13 firmadan sadece 3 tanesinde yıllık ortalama EVA değeri pozitiftir. Kalan 10 adedinin ortalamaları negatiftir. Aynı yıllarda dönem sonlarındaki hisse senedi fiyatları baz alınarak performansları değerlendirildiğinde, 10 yılda 10 ile 66 kat arasında artış sağlamış hisse senetleri olduğu görülmektedir. Bu durum, firmaların hisse değerlerinin katma değerden ziyade spekülatif olarak arttığını göstermektedir.

Ulusal literatürde bu konuda BİST Bilişim Endeksi'ne uygulanan benzer bir çalışma tespit edilmemiştir. Bununla birlikte başka endeks ve faaliyet alanlarına uygulanan çalışmalar vardır. Bu çalışmalar incelendiğinde araştırma yöntem ve istatistik biliminden faydalanma farklılıkları olduğu fark edilmiştir. Öyle ki tahmin modelini sadece korelasyon ile tamamlayanlar olduğu gibi regresyon analizi yaparak anlamsız katsayıların olduğu modeller ile yüksek açıklama gücü olduğunu bildiren sonuçlar tespit edilmiştir.

Bu çalışmanın farkı hem endeksin tamamına değil alt sektörlere bölümlendirme yaparak analiz yapması, hem de en iyi sonucu veren regresyon modeli için tüm bağımsız değişken kombinasyonlarının test edilerek titizlenilmesidir. 


\section{KAYNAKÇA}

Anderson, K., ve Brooks, C. (2006). Decomposing the Price-Earnings Ratio, Journal of Asset Management, 6 (6), $456-$ 469. https://doi.org/10.1057/palgrave.jam.2240195

Aslanoğlu, S., ve Zor, İ. (2006). Bilgi Varlıklarının Değerlemesi: Entelektüel Sermaye Ölçüm ve Değerleme Modelleri; Karşılaştırmalı Bir Analiz, Muhasebe ve Finansman Dergisi, (29), 152-165.

Aydeniz, E. Ş. (2009). Makroekonomik Göstergelerin Firmaların Finansal Performans Ölçütleri Üzerindeki Etkisinin Ölçülmesine Yönelik Bir Araştırma: İMKB'ye Kote Gıda Ve İçecek İşletmeleri Üzerine Bir Uygulama, Marmara Üniversitesi İktisadi ve İdari Bilimler Dergisi, 27 (2), 263-277.

Aydın, N., Başar, M., ve Coşkun, M. (2010). Finansal Yönetim, Ankara: Detay Yayıncılık.

Birkan, R. (2015, Haziran). Finansal Performansın Ölçülmesinde Ekonomik Katma Değer ve Bankacılık Sektöründe Piyasa Değer İle İlişkisinin Analizi, Ankara: Gazi Üniversitesi Sosyal Bilimler Enstitüsü, Doktora Tezi.

Büker, S., Aşıkoğlu, R., ve Sevil, G. (2009). Finansal Yönetim, Ankara: Sözkesen Matbaacılık.

Chan, J. (2020). Economic Value Added (EVA), https://www.investopedia.com/terms/e/eva.asp (Erişim tarihi: 10 Nisan 2020).

Çakıcı, C. (2008). Ekonomik Katma Değer (EVA) Yaklaşımı, İstanbul: Beta Yayınları.

Çelik, O. (2002, Mart). İşletmelerde Bir Performans Ölçütü Olarak Ekonomik Katma Değer (EKD) ve Türk Telekom A.Ş.' de Uygulanması, Muhasebe Bilim Dünyası, 4 (1), 21-55.

Draper, N. R., ve Smith, H. (1998). Applied Regression Analysis, New Jersey: John Wiley ve Sons, Inc. doi:10.1002/9781118625590

Emeç H. Durbin Watson Tablosu, http://kisi.deu.edu.tr//hamdi.emec/Yaz\%20Okulu/Ekonometri1/durbin\%20watson\%20tablosu\%20okuma .pdf (Erişim tarihi: 13 Nisan 2020).

Erem, I., ve Akyüz, Y. (2014). Piyasa Katma Değerini Açıklamada Ekonomik Katma Değerin Geleneksel Performans Ölçütleri Karşısındaki Durumunun İncelenmesi, Süleyman Demirel Üniversitesi İktisadi ve İdari Bilimler Fakültesi Dergisi, 19 (3), 371-385.

Goodman, D. A., ve Peavy, J. W. (1983). Industry Relative Price-Earnings Ratios as Indicators of Investment Returns, Financial Analysts Journal, 39 (4), 60-66. doi:https://doi.org/10.2469/faj.v39.n4.60

Gürbüz, A. O., ve Ergincan, Y. (2004). Şirket Değerlemesi Klasik ve Modern Yaklaşımlar, İstanbul: Literatür Yayıncılık.

Hayes, A. (2020). Return on Sales, https://www.investopedia.com/terms/r/ros.asp (Erişim tarihi: 09 Nisan 2020).

Higgins, R. (2009). Analysis for Financial Management, New York: McGraw Hill/lrwın.

Horasan, E., ve Yılmaz, T. (2019, Haziran). Türk İmalat Şirketlerinde Piyasa Katma Değerini (MVA) Açılayan Ekonomik Katma Değer mi Yoksa Karlılık mı?, Balıkesir Üniversitesi Sosyal Bilimler Enstitüsü Dergisi, 22 (41), 295-315. doi:10.31795/baunsobed.580589

İçke, B. T., ve Aytürk, Y. (2011, Ocak). Fiyat-Kazanç Oranı Etkisinin Değer Yatırım Stratejileri Kapsamında Analizi: İMKB İçin Amprik Bir Uygulama, Marmara Ünversitesi Sosyal Bilimler Enstitüsü Dergisi, 9 (35), 103-115.

İltaş, Y., ve Kaya, H. P. (2018). Ar-Ge Harcamalarının Hisse Başına Kara Etkisi: BİST Teknoloji Endeksi (XUTek) Firmaları Üzerine Bir Uygulama, Cumhuriyet Üniversitesi İktisadi ve İdari Bilimler Dergisi, 19 (1), 149-162.

Islam, R., Khan, T. R., Choudhury, T. T., ve Adnan, A. M. (2014). How Earning Per Share (EPS) Affects on Share Price and Firm Value, European Journal of Business and Management, 6 (17), 97-108. 
Kuğu, T. D., ve Kırlı, M. (2013). Ekonomik Katma Değer (Eva) Ölçütünün Sermaye Yapısı İle İlişkilendirilmesi: İMKB'de Bir Uygulama, Kahramanmaraş Sütçü İmam Üniversitesi İktisadi ve İdari Bilimler Fakültesi Dergisi, 3 (1), 171-180.

Mcclure, B. (2019), Investors Need a Good WACC, https://www.investopedia.com/articles/fundamental/03/061103.asp (Erişim tarihi: 13 Nisan 2020)

Nakhaei, H., ve Hamid, N. I. (2013). The Relationship Between Economic Value Added, Return on Assets, and Return on Equity with Market Value Added in Tehran Stock Exchange (TSE), Global Business and Finance Research Conference in Taipei, Taiwan, 28-29 October 2013, 1-9.

Önal, Y. B., Kandır, S. Y., ve Karadeniz, E. (2006). Piyasa Katma Değeri (MVA) İle Finansal Performans Ölçütleri Arasındaki İlişkinin Ölçülmesi: İMKB'ye Kote 5 Turizm İşletmesini Üzerine Bir Uygulama, Muhasebe ve Denetime Bakış Dergisi (20), 13-30.

Top, D. (2013). Ekonomik Katma Değer (EVA) ve Piyasa Katma Değeri'nin (MVA) Hisse Senedi Getirileri Üzerindeki Etkisi ve IMKK'de Bir Uygulama, Bolu: Abant İzzet Baysal Üniversitesi Sosyal Bilimler Enstitüsü, Yüksek Lisans Tezi.

Uysal, M., ve Günay, S. (2001). Durbin-Watson Ölçütüne Göre Kararsılılı Bölgesinde Bulunan Negatif Otokorelasyon İçin Bazı Testler, Anadolu Üniversitesi Bilim ve Teknoloji Dergisi, 2 (2), 277-284.

Weissenrieder, F. (1997). Value Based Management: Economic Value Added or Cash Value Added?, Gothenburg Studies in Financial Economics. doi:10.2139/ssrn.156288

Yavuz, S. (2009). Hataları Ardışık Bağımlı (Otokorelasyonlu) Olan Regresyon Modellerinin Tahmin Edilmesi, Atatürk Üniversitesi İktisadi ve İdari Bilimler Dergisi, 23 (3), 123-139. 